\title{
Neuro-Intensivists as Effective Resource Managers. No, Really
}

\author{
Andrew M. Naidech ${ }^{1}$
}

Published online: 29 August 2015

(c) Springer Science+Business Media New York 2015

Intensivists are known predominantly for the geographic location where they ply their trade. One might reasonably assume they are doing whatever it is patients need there, and perhaps the corollary, nudging out patients who no longer need critical care. How far should our influence go?

Metrics for desirable ICU care have evolved. No one is impressed by how many subclavian veins we can cannulate. On the contrary, as an ICU Director, I am continually under pressure to take all the central venous catheters out to minimize the risk of healthcare-acquired infections (HAIs). We expect our ICUs to be efficient, safe, patient-centered, family-centered, and improve later health-related quality of life in multiple domains [1].

Simultaneously, we are drowning in information like never before. A newly offered board certification in Clinical Informatics from the American Board of Preventive Medicine (http://www.theabpm.org/abpm_clinical_informatics. pdf) underscores that piecing together insights from data is now a serious pursuit. The ICU is the lab, but it is a strange one: an ongoing uncontrolled experiment that cannot ever cease but is continually nudged for optimization.

I read the paper under discussion [2] at this nexus of informatics and outcomes. Linking multiple data systems with a change in process, the data suggest that increasing the role of intensivists had salutary effects on ICU utilization. Mechanically ventilated patients were already seen by an intensivist, while involving an intensivist in all

Andrew M. Naidech

a-naidech@northwestern.edu

1 Northwestern U, 710 N Lake Shore Drive 11th Floor, Chicago, IL 60611, USA patients in the ICU reduced length of stay by about a calendar day, a saving carried through hospital discharge. Overall, the ICU spent less time on diversion and increased throughput, allowing more patients to potentially benefit. This increased throughput does not seem to have come at the expense of more infections or worse outcomes, so far as one can tell in the data.

Narrowly read, this manuscript implies intensivists are not only helpful for managing critically ill patients, but also speed less critically ill patients through the system through more efficient use of scarce resources. More broadly, these process improvement methods might be useful to improve any number of ICU processes, such as reducing HAIs [3]. This is likely to be of interest to hospital administrators, who are under increasing pressure to keep costs in line, efficiently utilize their staff, and minimize care for which the hospital is not compensated.

Just because these data could be counted does not mean these are all the data that count: There is not a lot of "neuro" in this manuscript for Neurocritical Care. More data on improving processes for neurologic evaluations [4] or complications (e.g., cerebral edema, vasospasm) would be of interest. Diagnoses are not given, so it is hard to tell how much intensivist staffing affected primary neurologic conditions (e.g., more rapid ICU discharge for patients with seizures quickly brought under control), or if these were more typical ICU conditions (e.g., pneumonia in patients with stroke). Medication administration data are not given, so it is difficult to tell if patient management evolved. There are no data on patient-centered outcomes after discharge, which would be helpful to tell if similar discharge disposition presaged other similar outcomes. These are questions that are potentially answerable with more data that may not reside in a typical electronic medical record. 
As professionals, did we sign up for (a) improving outcomes for patients with life-threatening neurologic disease (as it reads on the NCS website), (b) triage and disposition for the ICU (sometimes delegated to fellows), (c) on-the-job training in data mining (as many of us have managed in order to publish), or (d) managing scarce resources (as this paper suggests)? As usual, the best answer is (e) all of the above.

\section{References}

1. Naidech AM, Beaumont JL, Berman M, Francis B, Liotta E, Maas MB, Prabhakaran S, Holl J, Cella D. Dichotomous, "good outcome" indicates mobility more than cognitive or social quality of life. Crit Care Med. 2015;43:1654-9.

2. Rodricks MB, Hawkins SE, Anderson GA, Basignani C, Tuppeny M. Mandatory intensivist management decreases length of stay, facilitates an increase in admissions and minimizes closure of a neurocritical care unit. Neurocrit Care. 2015. doi:10.1007/s12028015-0148-3.

3. Schelling K, Palamone J, Thomas K, Naidech A, Silkaitis C, Henry J, Bolon M, Zembower TR. Reducing catheter-associated urinary tract infections in a neuro-spine intensive care unit. Am J Infect Control. 2015;43:892-4.

4. Maas MB, Rosenberg NF, Kosteva AR, Bauer RM, Guth JC, Liotta EM, Prabhakaran S, Naidech AM. Surveillance neuroimaging and neurologic examinations affect care for intracerebral hemorrhage. Neurology. 2013;81:107-12. 